\title{
Neutral endopeptidase activity in newborn and adult rabbit tracheas
}

\author{
K. Haver*, C. Gerard**, L. Kobzik*, S.A. Shore*
}

Neutral endopeptidase activity in newborn and adult rabbit tracheas. K. Haver, $C$. Gerard, L. Kobzik, S.A. Shore. (C)RS Journals Ltd 1997.

ABSTRACT: Neutral endopeptidase (NEP, E.C. 3.4.24.11), a widely distributed ectoenzyme, cleaves and inactivates a variety of biologically active peptides, including the tachykinin, substance $P$ (SP). This study was undertaken to determine whether the modulation of SP airway smooth muscle contraction by NEP is agedependent.

We studied the contractile response of isolated tracheal rings from newborn and 120 day old New Zealand white rabbits. We measured NEP activity and determined immunoreactive NEP content in tracheal membrane preparations. NEP activity was then localized histochemically in sections of rabbit tracheas.

In the presence of the NEP inhibitor, SCH 32615, the contractile response of isolated tracheal rings to SP was increased both in the newborn and $\mathbf{1 2 0}$ day old rabbits. However, the increase was greatest in the newborn animals. NEP activity in tracheal membrane preparations increased fivefold between the newborn and 120 day old rabbits. Western blot analysis also revealed a significant increase in the immunoreactive NEP content of these tracheal membrane preparations between the newborn and 120 day old rabbits. NEP activity, localized histochemically, was most intense in the epithelial region of the newborn animals, with a shift of activity to the subepithelial region with age.

The prominent epithelial localization of neutral endopeptidase in the tracheas of these 1 day old rabbits, which we have shown to have relatively low neutral endopeptidase activity, suggests that the location of neutral endopeptidase in the airway, including proximity to relevant substance $P$ receptors, may be critical to its function.

Eur Respir J 1997; 10: 1844-1849.
*Physiology Program, Harvard School of Public Health and **Ina Sue Perlmutter Laboratory at Children's Hospital, Boston, Massachusetts, USA.

Correspondence: K. Haver

Pulmonary Division

The Floating Hospital for Children

750 Washington Street

NEMC Box \#343

Boston

MA 0211

USA

Keywords: Contractile activity

fluorometric assay

histochemistry

substance P

Western blot analysis

Received: May 61996

Accepted after revision February 241997

This work was supported by HL19170 and HL07633 from the National Institutes of Health, National Heart Lung and Blood Institute.
Neutral endopeptidase (NEP; EC 3.4.24.11) is a highly conserved cell membrane-associated enzyme, which has been found in neural and nonneural tissues, including the brain, kidney, intestine, male reproductive organs and placenta [1]. NEP activity has also been detected in the lungs and airways of a number of species $[2,3]$, including humans $[4,5]$. In the lung, NEP has been localized to airway smooth muscle, fibroblasts, chondrocytes, perichondrium, submucous gland epithelial cells, airway epithelium, and the lung parenchyma [3,5]. NEP cleaves and inactivates a wide variety of biologically active peptides involved in functions as diverse as the regulation of blood pressure [6], chemotaxis [7], and the regulation of foetal lung growth and maturation [8].

Recently, a great deal of interest has been focused on the ability of NEP to cleave tachykinins released from C-fibres in the airways. Both animal studies and studies in human airways have shown that by degrading substance P (SP) and neurokinin A, NEP limits the capacity of these peptides to contract airway smooth muscle, to induce mucous secretion, and to increase vascular permeability [4]. NEP also appears to be involved in limiting the airway responses to other mediators, which may act, in part, by releasing tachykinins from $\mathrm{C}$-fibres to induce effects $[9,10]$. The responsiveness of the airways to a variety of mediators, including SP, decreases with age $[11,12]$. Since metabolism by NEP influences the action of peptide mediators, we reasoned that maturational changes in NEP could have important functional implications. To explore this hypothesis, we studied the contractile response of isolated tracheal rings to SP in the presence and absence of the NEP inhibitor, SCH 32615. We then measured the NEP activity and immunoreactive content in rabbit tracheas. Finally, we localized NEP activity, histochemically, in tracheal sections from rabbits of different ages.

\section{Methods}

\section{Contractile response to $S P$}

One and 120 day old barrier-reared male New Zealand white rabbits were euthanized with an intraperitoneal overdose of sodium pentobarbital. The age of 120 days was selected because rabbits are considered to be fully mature when they are 105-140 days of age, weigh 3-3.5 $\mathrm{kg}$, and are capable of reproducing. The trachea and lungs were removed en bloc and placed into Krebs-Henseleit 
solution, pH 7.5 (composition mM: $\mathrm{NaCl} 118.4, \mathrm{KCl}$ 4.7, $\mathrm{CaCl}_{2} 2 \mathrm{H}_{2} \mathrm{O}$ 2.5, $\mathrm{MgSO}_{4} \cdot 7 \mathrm{H}_{2} \mathrm{O}$ 1.2, $\mathrm{KH}_{2} \mathrm{PO}_{4}$ 1.2, $\mathrm{NaHCO}_{3} 25.0$, and (+)-glucose 11.1) aerated with 5\% $\mathrm{CO}_{2}$ in $\mathrm{O}_{2}$. Adjacent tracheal rings were suspended between stainless steel hooks under a 1 or $2 \mathrm{~g}$ load for the $1(n=6)$ and 120 day old $(n=7)$ preparations, respectively, in organ baths containing Krebs-Henseleit solution. The baths were maintained at $37^{\circ} \mathrm{C}$ with circulating water jackets, and aerated with $5 \% \mathrm{CO}_{2}$ in $\mathrm{O}_{2}$. The tissues were allowed to equilibrate over $1 \mathrm{~h}$ with a solution change every $20 \mathrm{~min}$.

Changes in tension were measured isometrically with Grass FT.03 transducers (Warwick, RI, USA). At the end of the period of equilibration, SCH 32615 (N-(L-(1-carboxy-2 phenyl)-ethyl)-L-phenylalanyl-beta-alanine) (10-5 $\mathrm{M}$ final concentration) [13] was added to one of each pair of tissue baths containing adjacent tracheal sections. Cumulative concentration-responses to SP $\left(10^{-9}\right.$ $\left.10^{-5} \mathrm{M}\right)$ were then obtained. At the end of the concentration-response curve, following several changes in bathing solution and re-establishment of baseline tone, acetylcholine $(\mathrm{ACh})\left(10^{-3} \mathrm{M}\right)$ was added to each bath and the contractile plateau was recorded. Responses to SP were normalized to the response obtained with ACh $\left(10^{-3} \mathrm{M}\right)$.

NEP activity in tracheal membrane preparations from rabbits of different ages

The tracheas of 1 and 120 day old rabbits were removed, immediately placed in liquid nitrogen, and stored at $-80^{\circ} \mathrm{C}$ until use. Using a modification of the methodology of ORLOWSKI and WILK [14], tissues for membrane preparations were thawed before adding five volumes of cold $0.02 \mathrm{M}$ sodium phosphate buffer, $\mathrm{pH} 8.0$, with $0.25 \mathrm{M}$ sucrose, followed by homogenization with a Teflon-coated probe for three $10 \mathrm{~s}$ pulses (setting 6) (Brinkman, Westbury, NY, USA). Samples were then centrifuged at $5,000 \times \mathrm{g}$ for $20 \mathrm{~min}$. The pellet was discarded, the supernatant was brought to a final concentration of $100 \mathrm{mM}$ zinc sulphate, and the $\mathrm{pH}$ was adjusted to 5.2 by the addition of $20 \%$ acetic acid. The samples were then centrifuged at $15,000 \times \mathrm{g}$ for $30 \mathrm{~min}$, the supernatant discarded, and the pellets resuspended in $5 \mathrm{~mL}$ Tris buffer, $\mathrm{pH} 7.0$, with $2 \%$ Triton X-100. The suspensions were transferred to a $15 \mathrm{~mL}$ glass homogenizer and brought to uniform consistency. The membrane preparations were then incubated at $37^{\circ} \mathrm{C}$ in a water bath for $1 \mathrm{~h}$, followed by centrifugation at $30,000 \times \mathrm{g}$ for $1 \mathrm{~h}$. The supernatant with solubilized enzyme was stored at $-80^{\circ} \mathrm{C}$ until use.

\section{Determination of enzyme activity}

Aliquots of the membrane preparations were added, in duplicate, to an excess of NEP substrate, Glu-AlaAla-Phe-alpha-methylcoumarin $\left(5 \times 10^{4} \mathrm{M}\right)$ (Enzyme Systems Products, Livermore, CA, USA) in $45 \mu \mathrm{L}$ of $0.5 \mathrm{M}$ 2-(N-morpholine) ethanosulphonic acid (MES) buffer (Spectrum, Gardena, CA, USA), $\mathrm{pH}$ 6.5, with 0.5\% Triton X-100. Phe-7-amino-4-methylcoumarin (AMC) complexes were produced following NEP cleavage during a 45 min incubation, following zero order kinetics (data not shown), in a water bath maintained at $37^{\circ} \mathrm{C}$. Enzyme activity was halted by the addition of dithiothreitol (final concentration $1 \mathrm{mM}$ ). Porcine renal aminopeptidase M, 1.3 U, (Calbiochem, La Jolla, CA, USA) was added to each reaction mixture, followed by incubation for an additional $10 \mathrm{~min}$ at $37^{\circ} \mathrm{C}$ to liberate the AMC moiety.

The samples were placed on ice, transferred to a 96well Pro-Bind microtitre plate (Becton Dickinson, Lincoln Park, NJ, USA) and analysed in a CytoFluor 2300 (Millipore, New Bedford, MA, USA), with an excitation wavelength of $360 \mathrm{~nm}$ and emission wavelength of $460 \mathrm{~nm}$. Free AMC was used as a standard. Protein content of the membrane preparations was determined, in duplicate, using the Bio-Rad protein assay (Bio-Rad Laboratories, Richmond, CA, USA). The selective NEP inhibitor, SCH 32615, was added to duplicate samples. Enzyme activity is reported as the nanomoles of AMC liberated $\cdot \mathrm{mg}$ protein ${ }^{-1} \cdot \mathrm{h}^{-1}$, which was inhibited by $10^{-5}$ M SCH 32615.

\section{Western blot analysis}

Membrane preparations from the tracheas of newborn and 120 day old male New Zealand white rabbits (10 $\mu \mathrm{g}$ per lane) were subjected to $12 \%$ polyacrylamide gel electrophoresis in the presence of sodium dodecylsulphate (SDS-PAGE). The gel was then placed in a semi-dry electroblot apparatus (Integration Separation Systems, Hyde Park, MA, USA), with an Immobilon P membrane (Millipore, Bedford, MA, USA) on the anode side, and the protein transferred at $50 \mathrm{~mA}$ for $1 \mathrm{~h}$ at room temperature. Nonspecific staining was blocked with phosphate-buffered saline (PBS), pH 7.5, containing 5\% instant nonfat milk.

The Immobilon $\mathrm{P}$ membrane was incubated with a polyclonal rabbit anti-rat kidney NEP antibody (gift from Dr L. Hersh) at a dilution of 1:1000 in PBS with $5 \%$ milk for $2 \mathrm{~h}$ at room temperature. This antibody has previously been judged to be monospecific against denatured NEP, recognizing a single band of the same molecular weight as pure NEP from a crude rat kidney homogenate [14], and has also been reported to identify NEP in Western blot analyses $[15,16]$. The Immobilon $\mathrm{P}$ membrane was then washed with PBS for 30 min with buffer changes every $10 \mathrm{~min}$.

Horseradish peroxidase-anti-immunoglobulin (Ig) conjugate (Vectastain, Burlingame, CA, USA) was diluted 1:1000 in PBS and incubated with the Immobilon P membrane for $1.5 \mathrm{~h}$ at room temperature. The Immobilon $\mathrm{P}$ membrane was again washed in PBS for $30 \mathrm{~min}$ with buffer changes every $10 \mathrm{~min}$. Diaminobenzidine substrate solution $\left(1 \mu \mathrm{g} \cdot \mathrm{mL}^{-1}\right.$ in PBS with $0.1 \%$ hydrogen peroxide) was then added and allowed to develop for approximately $2 \mathrm{~min}$. The reaction was stopped by washing with tap water. Photographs of the Immobilon $\mathrm{P}$ membranes were electronically scanned (Apple One Scanner, Campbell, CA, USA) and the relative density of the gel bands were determined using a personal computer-based image analysis program (NIH Image version 1.41, Bethesda, MD, USA). 


\section{NEP histochemistry}

This method, modified from the methods of BACK and GoRENSTEIN [17], is based on the sequential cleavage of the synthetic NEP substrate glutaryl-ala-ala-phe-4-methoxy-2-naphthylamide (GaapMNA) (Enzyme Systems Products, Livermore, CA, USA) by NEP and aminopeptidase to yield free MNA. Free MNA then reacts with fast blue B (Fisher, Pittsburgh, PA, USA) yielding an insoluble orange precipitate visible by light microscopy. Sections of newborn $(n=4)$ and 120 day old $(n=5)$ rabbit tracheas, fixed with $2 \%$ paraformaldehyde, were reacted with 0.5 mM GaapMNA in Tris- $\mathrm{HCl}$ buffer, $\mathrm{pH} 7.4$, with 0.5 $\mathrm{mg} \cdot \mathrm{mL}^{-1}$ fast blue salt. Sections were incubated for 2 $\mathrm{h}$ at $37^{\circ} \mathrm{C}$, rinsed, and mounted with aqueous glycerol mounting medium. Formation of the precipitate was inhibited by the addition of $10^{-6}$ M SCH 32615 to the incubation medium, verifying that the formation of the product was the result of hydrolysis by NEP.

\section{Statistical analysis}

Differences in contractile responses, normalized to the response obtained with ACh $\left(10^{-3} \mathrm{M}\right)$, were assessed by means of a two-tailed Student's t-test for paired data. Differences were considered significant at a p-value equal to or less than 0.05 . Comparisons of NEP activity and relative densities of gel bands between groups of
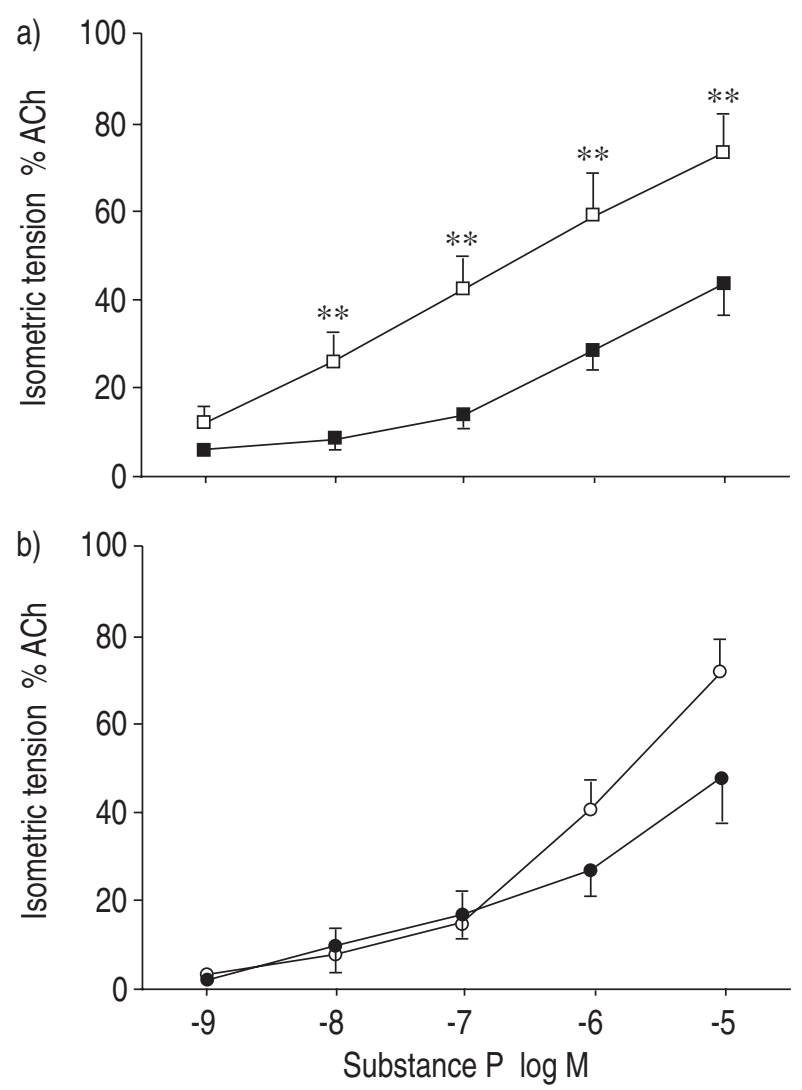

Fig. 1. - The effect of substance $\mathrm{P}$ on the isometric force generation in: a) 1 day old $(n=6)$, and b) 120 day old $(n=7)$ rabbit tracheal rings in the absence (closed symbols) and presence (open symbols) of SCH $32615\left(10^{-5} \mathrm{M}\right.$ final concentration). Data are represented as a percentage of the response to ACh $\left(10^{-3} \mathrm{M}\right)$. **: $\mathrm{p} \leq 0.01$ rabbits of different ages were made using analysis of variance (ANOVA). Follow-up t-tests were performed with corrections for multiple comparisons.

\section{Results}

\section{Contractile response to $S P$}

SP produced concentration dependent-contraction in tracheal sections from newborn and 120 day old rabbits (fig. 1). In control tissues, responses to SP were approximately the same in the newborn $(n=6)$ and 120 day old $(n=7)$ animals. Inhibition of NEP with SCH 32615 enhanced the contractile response to SP to a greater extent in the newborn $(n=6)$ than in the 120 day old $(n=7)$ animals. In the presence of the NEP inhibitor, $\mathrm{SCH}$ 32615 , the increase in contractile response of isolated tracheal rings to $\mathrm{SP}\left(10^{-5} \mathrm{M}\right)$ was more than $50 \%$ greater in the younger animals than in the older animals (fig. $1)$.

\section{NEP activity in tracheal membrane preparations from} rabbits of different ages

To determine whether differences in NEP activity contributed to the differing effects of SCH 32615 on contractile response to SP with age, NEP activity was measured in membrane preparations of the tracheas from newborn and 120 day old rabbits. However, in contrast to the effects of SCH 32615 on contractile responses to SP (fig. 1), NEP activity was more than fivefold greater in 120 day old $(102.7 \pm 8.26 \mathrm{nmol}$ substrate cleaved $\cdot m g$ protein ${ }^{-1} \cdot \mathrm{h}^{-1} ; \mathrm{n}=6$ ) than in 1 day old rabbits $\left(19.86 \pm 8.59 \mathrm{nmol}\right.$ substrate cleaved $\cdot \mathrm{mg}$ protein $^{-1} \cdot \mathrm{h}^{-1}$; $\mathrm{n}=5)(\mathrm{p}<0.01)$ (fig. 2). SCH 32615 caused similar concentration-dependent inhibition of NEP activity in both preparations.

Western blot analysis of tracheal membrane preparations from newborn and fully mature rabbits

In order to determine whether the increase in NEP activity measured with age was due to an increase in NEP protein, the same membrane preparations were

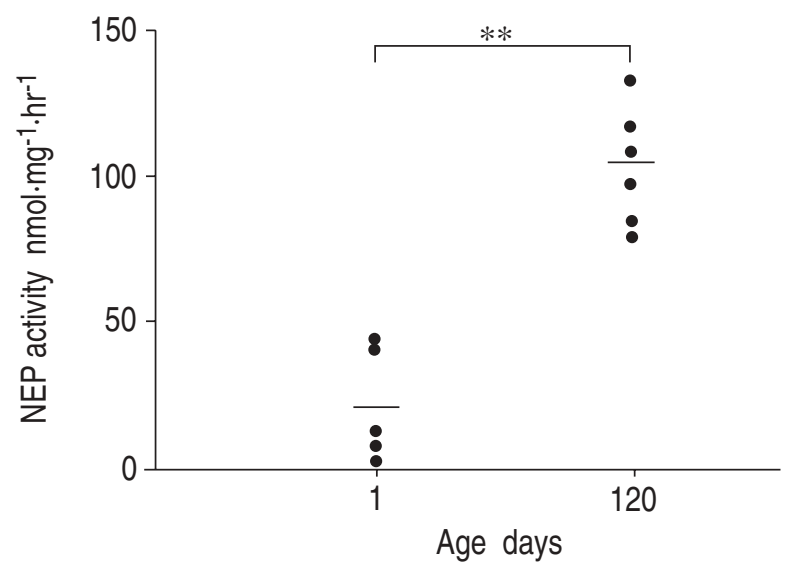

Fig. 2. - The relationship between rabbit age and neutral endopeptidase (NEP) activity in tracheal membrane preparations from 1 and 120 day old rabbits. Each point represents an individual rabbit. Means are represented by horizontal bars. $* *: p \leq 0.01$. 
subjected to Western blot analysis. A polyclonal rabbit anti-rat NEP antibody labelled a discrete band corresponding to the molecular weight of NEP (approximately $90 \mathrm{kDa}$ [14], following SDS-PAGE fractionation of these rabbit tracheal membrane preparations (fig. 3). The mean intensity of this band increased with age between 1 day (302 \pm 106 arbitrary intensity units $(\mathrm{au}) ; \mathrm{n}=6)$ and 120 days $(2284 \pm 290 \mathrm{au} ; \mathrm{n}=6)(\mathrm{p}<0.01)$ (fig. 4$)$. The minor band, which probably represents a glycosylation variant [16], has been reported previously $[15,16]$.

Histochemical localization of NEP activity in the tracheas of rabbits of different ages

NEP activity, reflected by an increase in NEP protein, increased with age. We had expected that the effect of the NEP inhibitor, SCH 32615, would be greater in the tissues exhibiting greater NEP activity, i.e. in tracheas from older animals. However, we found that NEP inhibition had a greater effect, potentiating responses to SP in tracheas from the newborn rabbits, which had the least NEP activity (fig. 1).

In order to determine whether there were age-related differences in the locus of NEP activity, rather than the total amount of NEP activity, that might explain the differences in the effects of NEP inhibition on the contractile responses to SP with age, a histochemical technique was used to visualize NEP. NEP activity was observed in the epithelial and subepithelial region in sections of tracheas from newborn and 120 day old rabbit tracheas (fig. 5a and c). The addition of $10^{-6} \mathrm{M} \mathrm{SCH}$

STO

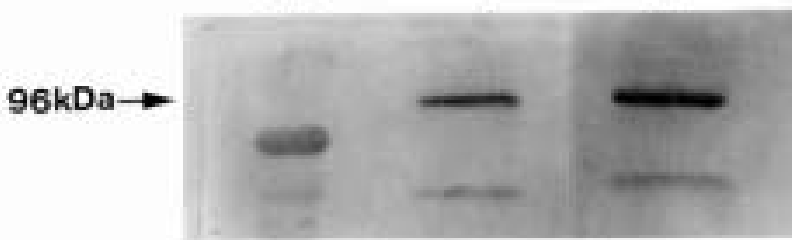

Fig. 3. - A representative Western blot analysis demonstrating increase in neutral endopeptidase (NEP) immunoreactive content from 1 (lane 1) and 120 (lane 2) day old rabbit tracheal membrane preparations. Equal amounts of protein $\left(10 \mu \mathrm{g} \cdot \mathrm{lane}^{-1}\right)$ were probed with a polyclonal rabbit anti-rat NEP antibody (see text). Molecular weight standards (STD) are shown at left.

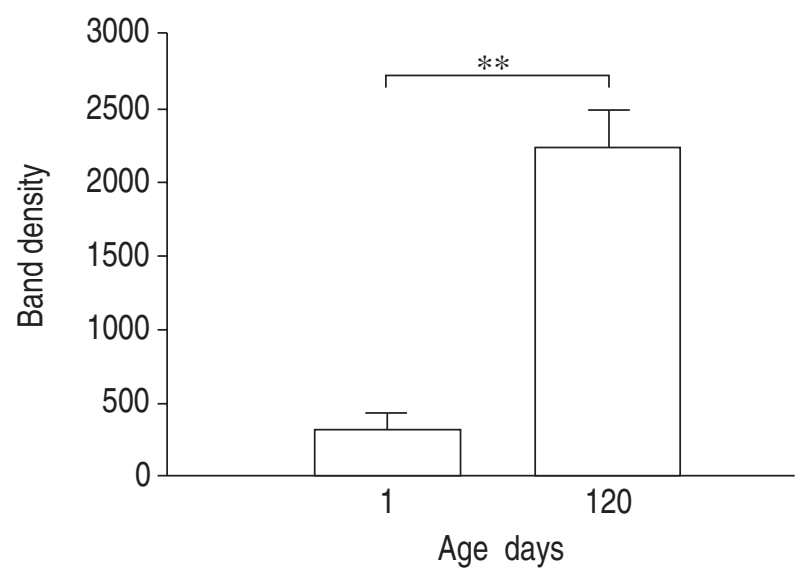

Fig. 4. - Densitometric analysis of Western blots $(n=6)$ detecting immunoreactive neutral endopeptidase (NEP) content of 1 and 120 day old rabbit tracheal membrane preparations. Results are presented as mean \pm SEM. $* *: \mathrm{p} \leq 0.01$.
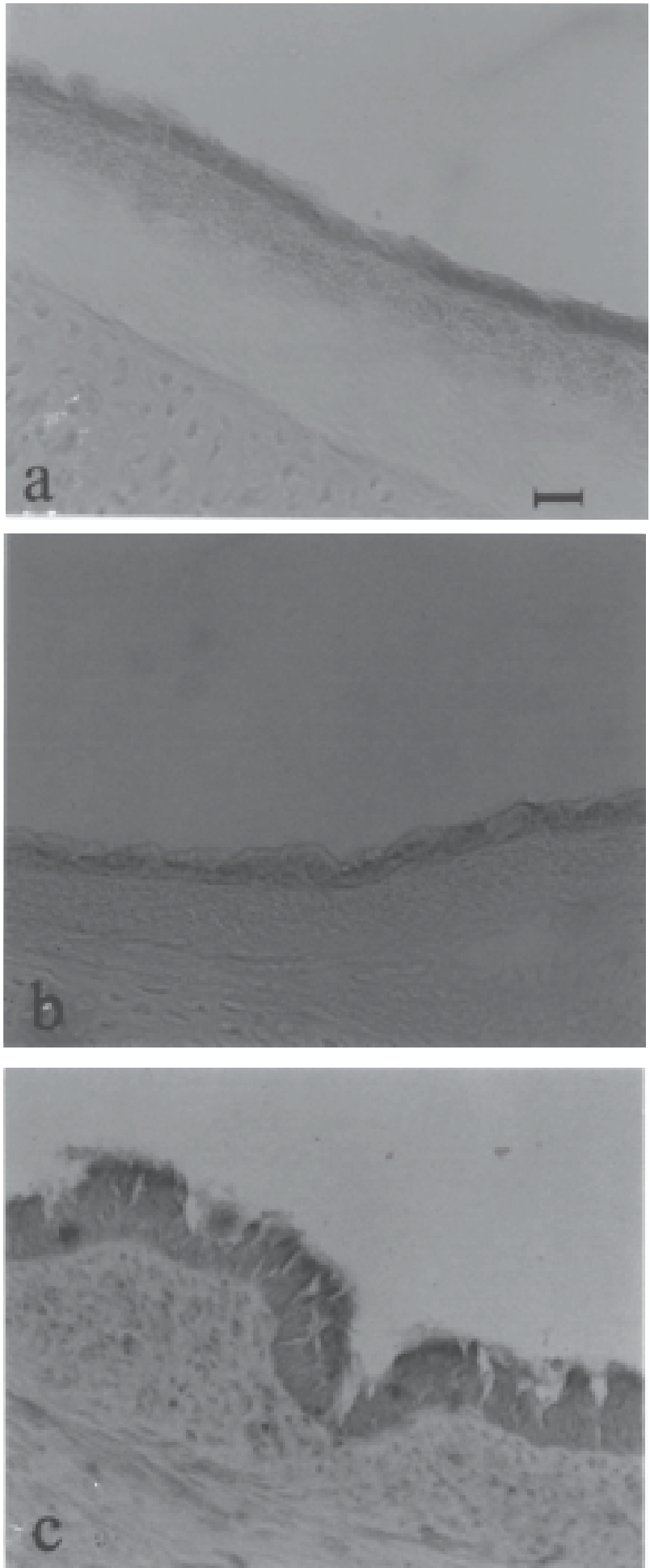

Fig. 5. - Histochemical staining of sections from 1 and 120 day old rabbit trachea demonstrates neutral endopeptidase (NEP) activity (see text), predominantly in: a) the epithelial region of the 1 day old and c) the subepithelial region in the 120 day old rabbits. b) Staining was reduced to background levels by pre-incubating the section with a NEP inhibitor, $10^{-6}$ M SCH 32615. Internal scale bars $=100 \mu \mathrm{m}$.

32615 to the incubation medium to sequential sections blocked the formation of the precipitate (fig. 5b), verifying that this was indeed the result of NEP hydrolysis of the substrate. The sites of NEP activity changed with age. In the newborn animals, NEP activity was most 
pronounced in the epithelium (fig. 5a). The NEP epithelial staining intensity diminished with age, while the subepithelial staining increased in intensity with age, being most pronounced in the tracheas of the 120 day old animals (fig. 5c).

\section{Discussion}

We have shown that the NEP inhibitor, SCH 32615, causes a greater enhancement of the contractile response to SP in tracheal rings of newborn than 120 day old rabbits. In contrast to the effects of SCH 32615 on SPinduced contraction, we found that NEP activity was substantially greater in the 120 day old than in the 1 day old rabbits (fig. 2). The increase in NEP activity was also reflected in a greater amount of NEP protein, as determined by Western blot analysis (figs. 3 and 4). We demonstrated that the site of NEP activity, localized histochemically, shifted from the epithelial region in the tracheas of the newborn rabbits to the subepithelial region in older rabbits (fig. 5).

We showed that the NEP inhibitor, SCH 32615, enhances tracheal contractions to SP both in newborn and 120 day old rabbits. However, we found that the contractile response was increased to a greater extent in the newborn than in the 120 day old rabbit tracheal rings. Increasing the concentration of SCH 32615 had no further effect on the contractile response (data not shown), suggesting that NEP activity had been maximally inhibited in both preparations. Similar observations have been reported by COLASURDO et al. [18]. They found that inhibition of NEP with phosphoramidon enhanced the contractile response of tracheal rings to SP both in 1 and 12 week old rabbits, and that the effect was more pronounced in the younger animals. Thus, even though total NEP activity and NEP content were greater in the 120 day old than in the 1 day old rabbit tracheas (fig. 2), NEP degradation of SP appears to be much more important in modulating contraction in the tracheas of the younger rabbits.

One potential explanation for the greater effects of SCH 32615 in the newborn rabbit tracheas (fig. 1), despite a reduced total NEP activity and content (fig. 2), is that the site of NEP activity (fig. 5), rather than the total amount, is critical to its function. Epithelial NEP activity is important in modulating contractile responses of airways to SP $[18,19]$; removal of the epithelium from 16-20 week old Japanese white rabbit tracheas enhanced contractile responses to SP; however, no difference was seen in the contractile response to SP between intact and epithelium-denuded preparations in the presence of a NEP inhibitor [19]. COLASURDO et al. [18], in a preliminary report, showed that epithelial removal increased responses of tracheal rings to SP in 1 week old rabbits, but not in adults. We observed, in the younger animals, that NEP activity was most pronounced in the epithelium (fig. 5). This epithelial NEP staining diminished with age. In the older rabbits, NEP activity in the subepithelial region increased in intensity (fig. 5c). The importance of epithelial NEP for modifying contractile activity induced by SP, in conjunction with the prominent epithelial location of NEP in the younger animals (fig. 5a), may explain the greater effect of NEP in modifying contractile functions in these animals.

The determinations of enzyme activity were normalized to the total protein concentration of the tracheal membrane preparations. Changes in the contribution of the constitutive tracheal elements to the total tracheal protein content with age, in conjunction with differences in the expression of NEP across various elements, could produce a relative increase in the determinations of protein content (fig. 4), and subsequently, NEP activity (fig. 2). We detected a reduction in tracheal epithelial NEP histochemical staining with age, with a concomitant increase in subepithelial NEP activity (fig. 5). Thus, our findings suggest that, while total NEP activity increases with age in tracheal homogenates, the level of activity varies in different regions of the trachea.

We have detected NEP activity in newborn rabbit tracheas and observed an increase in activity with age (fig. 2). Postgestational changes in NEP activity have also been reported in the tracheas of piglets between ages $<4$ days and 10 weeks [2, 20]. In the rat lung, levels of NEP doubled in the first two postgestational weeks [21]. Increases in NEP activity with age have also been seen in other organs. In rat striatum, enkephalinase, which has recently been found to be homologous to NEP [14, $22]$, was shown to increase sixfold during postnatal development [23].

In conclusion, our results indicate that enhancement of the contractile response to substance $\mathrm{P}$ by inhibition of neutral endopeptidase is greater in the 1 day old than in 120 day old rabbits. In contrast, total neutral endopeptidase tracheal activity and neutral endopeptidase protein content are greater in the 120 day old than in the 1 day old rabbits. One possible explanation for the greater ability of SCH 32615 to augment contractile responses to substance $\mathrm{P}$ in the newborn versus adult tracheas is that the site of neutral endopeptidase activity is more important than either total neutral endopeptidase activity or neutral endopeptidase protein content. Given the importance of the epithelium in modulating the contractile response of the airways to substance $\mathrm{P}$, the prominent localization of neutral endopeptidase in the epithelium of the newborn animals may have important functional consequences. The modulatory effect of neutral endopeptidase on substance P-induced airway smooth muscle contraction, and perhaps the actions of other peptide mediators, may be tissue site-specific.

\section{References}

1. Erdos G, Skidgel RA. Human neutral endopeptidase 24.11 (NEP, enkephalinase): function, distribution and release. Adv Exp Med Biol 1988; 240: 13-21.

2. Haxhiu-Poskurica B, Haxhiu MA, Kuma GK, Miller MJ, Martin RJ. Tracheal smooth muscle responses to substance $\mathrm{P}$ and neurokinin $\mathrm{A}$ in the piglet. $J$ Appl Physiol 1992; 72(3): 1090-1095.

3. Kummer W, Fischer A. Tissue distribution of neutral endopeptidase 24.11 ("enkephalinase") activity in guineapig trachea. Neuropeptides 1991; 18: 181-186.

4. Joos GF, Germonpre JC, Peleman RA, Pauwels RA. Sensory neuropeptides and the human lower airways: present state and future directions. Eur Respir J 1994; 7: 1161-1171. 
5. Cohen AJ, Bunn PA, Franklin W, et al. Neutral endopeptidase: Variable expression in human lung, inactivation in lung cancer, and modulation of peptide-induced calcium flux. Cancer Res 1996; 56(4): 831-839.

6. Gros C, A Souque A, Schwartz JC, et al. Protection of atrial natriuretic factor against degradation: diuretic and natriuretic responses after in vivo inhibition of enkephalinase (EC 3.4.24.11) by acetorphan. Proc Natl Acad Sci USA 1989; 86: 7580-7584.

7. Connelly JC, Skidgel RA, Schulz WW, Johnson AR, Erdos EG. Neutral endopeptidase 24.11 in human neutrophils: cleavage of chemotactic peptide. Proc Natl Acad Sci USA 1985; 82(24): 8737-8741.

8. King KA, Hua J, Torday JS, et al. CD10/neutral endopeptidase 24.11 regulates fetal lung growth and maturation in utero by potentiating endogenous bombesin-like peptides. J Clin Invest 1993; 91(5): 1969-1973.

9. Kohrogi H, Yamaguchi T, Kawanoo O, Hondo I, Ando $\mathrm{M}$, Araki S. Inhibition of neutral endopeptidase potentiates bronchial contraction induced by immune response in guinea-pigs in vitro. Am Rev Respir Dis 1991; 144: 636-641.

10. Martins MA, Shore SA, Drazen JM. Release of tachykinins by histamine, methacholine, PAF, $\mathrm{LTD}_{4}$, and substance-P from guinea-pig lungs. Am J Physiol 1991; 261: L449-L455.

11. Grunstein MM, Tanaka DT, Grunstein JS. Mechanism of substance P-induced bronchoconstriction in maturing rabbit. J Appl Physiol: Respirat Environ Exercise Physiol 1984; 47(4): 1238-1246.

12. Preuss JM, Henry PJ, Goldie RG. Influence of age on epithelium-dependent responsiveness of guinea-pig and rat tracheal smooth muscle to spasmogens. Eur J Pharmacol 1992; 228(1): 3-8.

13. Chipkin RE, Berger JE, Billard W, Iorio LC, Chapman R, Barnett A. Pharmacology of SCH 34826, an orally active enkephalinase inhibitor analgesic. J Pharmacol Exp Ther 1988; 245(3): 829-838.

14. Orlowski M, Wilk S. Purification and specificity mem- brane-bound metalloendopeptidase from bovine pituitaries. Biochemistry 1981; 20(17): 4942-4950.

15. Bateman RC Jr, Jackson D, Slaughter CA, et al. Identification of the active-site arginine in rat neutral endopeptidase 24.11 (enkephalinase) as arginine 102 and analysis of a glutamine 102 mutant. J Biol Chem 1989; 264(11): 6151-6157.

16. Iijyma H, Gerard NP, Squassoni C, et al. Exon 16 del: a novel form of human neutral endopeptidase (CALLA). Am J Physiol 1992; 262 (Lung Cell Mol Physiol 6): L725-L729.

17. Back SA, Gorenstein C. Histochemical visualization of neutral endopeptidase-24.11 (enkephalinase activity in rat brain): cellular localization and co-distribution with enkephalins in the globus pallidus. J Neuroscience 1989; 9(12): 4439-4455.

18. Colasurdo GN, Loader JE, Graves JP, Larsen GL. Substance P-induced contraction of airway smooth muscle in young and adult rabbits: effects of epithelium removal and neutral endopeptidase inhibition. Chest 1995; 107 (3 Suppl.): 126s.

19. Inoue K, Sakai Y, Homma I. An ubiquitous modulating function of rabbit tracheal epithelium: degradation of tachykinins. Br J Pharmacol 1992; 105: 393-399.

20. Dreshaj IA, Martin RJ, Miller MJ, Haxhiu MA. Responses of lung parenchyma and airways to tachykinin peptides in piglets. $J$ Appl Physiol 1994; 77(1): 147-145.

21. Dutriez I, Sales N, Fournie-Zaluski M-C, Roques BP. Pre- and postnatal ontogeny of neutral endopeptidase 24-11 ("enkephalinase") studied by in vitro autoradiography in the rat. Experientia 1992; 48: 290-300.

22. Malfroy B, Schofield PR, Kuang WJ, Seeburg PH, Mason AJ, Hanzel WJ. Molecular cloning and amino acid sequence of rat enkephalinase. Biochem Biophys Res Commun 1987; 144: 59-66.

23. Patey G, de la Baume S, Gros C, Schartz J-C. Ontogenesis of enkephalinergic systems in rat brain: postnatal changes in enkephalin levels, receptors and degrading enzyme activities. Life Sci 1980; 27(3): 245-252. 